\title{
CULTURA ESCRITA Y TECNOCULTURA CONTEMPORÁNEA: MEDIACIONES COGNITIVAS EN LA FORMACIÓN UNIVERSITARIA
}

Por:

Giovanna Carvajal Barrios ${ }^{1}$

Profesora asociada

Escuela de Comunicación Social

Universidad del Valle

giovanacarv@hotmail.com

\section{Alejandro Ulloa}

Profesor titular

Escuela de Comunicación Social

Universidad del Valle

ausa52@hotmail.com

\section{Resumen:}

En este artículo se presentan parte de los resultados de una investigación que aborda las relaciones entre cultura escrita, conocimiento y tecnocultura en la Universidad del Valle (Colombia). El estudio se desarrolló en dos fases, con un mismo grupo de estudiantes, de tal manera que fue posible establecer un contraste entre los resultados obtenidos en cada una de ellas.

Palabras claves: lectura, escritura, cultura escrita, tecnocultura, conocimiento.

\begin{abstract}
:
In this article is presented a part of the results of an investigation about the relations between written culture, knowledge and tecnoculture at Universidad del Valle (Colombia). The work was developed in two phases with the same group of students. In that way it was possible established a contrast between the results at each phase.
\end{abstract}

Keywords: reading, writing, written culture, tecnoculture, knowledge. 
En este artículo se presentan parte de los resultados de una investigación que aborda las relaciones entre cultura escrita, conocimiento y tecnocultura en la Universidad del Valle (Colombia). El estudio se desarrolló en dos fases, con un mismo grupo de estudiantes, de tal manera que fue posible establecer un contraste entre los resultados obtenidos en cada una de ellas.

En la primera fase (2003-2004), realizada con 260 estudiantes de segundo semestre de todos los programas académicos, se aplicaron los siguientes instrumentos metodológicos²: (a) Una encuesta sobre prácticas de lectura y escritura y uso de tecnologías de comunicación e información, incluida la escritura, antes y después del ingreso a la universidad. (b) Una prueba de lectura y escritura de textos expositivoargumentativos, como una forma de indagar por su relación con la cultura escrita. Se analizaron los resultados de manera independiente y se realizó un

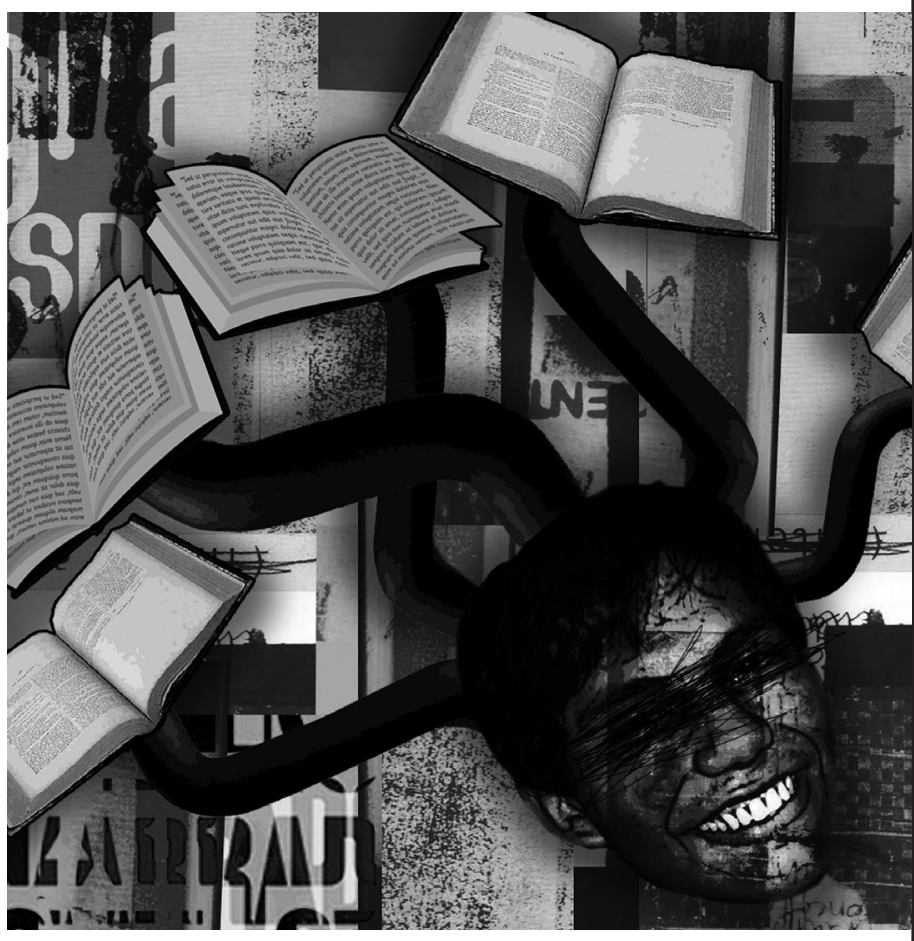
cruce de variables, de cuyas conclusiones surgieron nuevas hipótesis.

En la segunda fase (2007-2009) ${ }^{3}$, se aplicó una prueba similar a la primera, esta vez a 20 de los 260 estudiantes. Se realizó, además, una entrevista que ampliaba la información aportada por la encuesta inicial de 2003, se revisó su ficha académica y se analizó un corpus de textos escritos por ellos durante su permanencia en la universidad.

En el artículo se hace una presentación parcial del marco teórico y se expone una síntesis de los resultados obtenidos en ambas fases de la investigación.

\section{Marco conceptual: cultura escrita, tecnocultura y conocimiento}

\subsection{La escritura: una tecnología y una institución social}

La escritura es una invención del hombre; es la tecnología de información y comunicación más antigua de todas; ha tenido innumerables transformaciones desde sus orígenes, hace más de tres mil años, hasta nuestra época.

La escritura como tecnología comprende dos dimensiones: una dimensión material (el alfabeto) y una dimensión subjetiva (los conocimientos necesarios para su uso y funcionamiento) ${ }^{4}$. Desde un punto de vista externo, la escritura es un artefacto inventado por el hombre que reduce el sonido, invisible y efímero, a una forma visual y duradera en el espacio, ya que el alfabeto representa el sonido asociado a un sentido, dentro de un sistema lingüístico determinado. Para la escritura se requiere de instrumentos con qué escribir y sobre los cuales escribir, desde el uso de la arcilla y el papiro hasta el manuscrito, el papel y la pantalla electrónica con sus correspondientes implementos: el cincel, la pluma, el lápiz, el mouse y el teclado. 


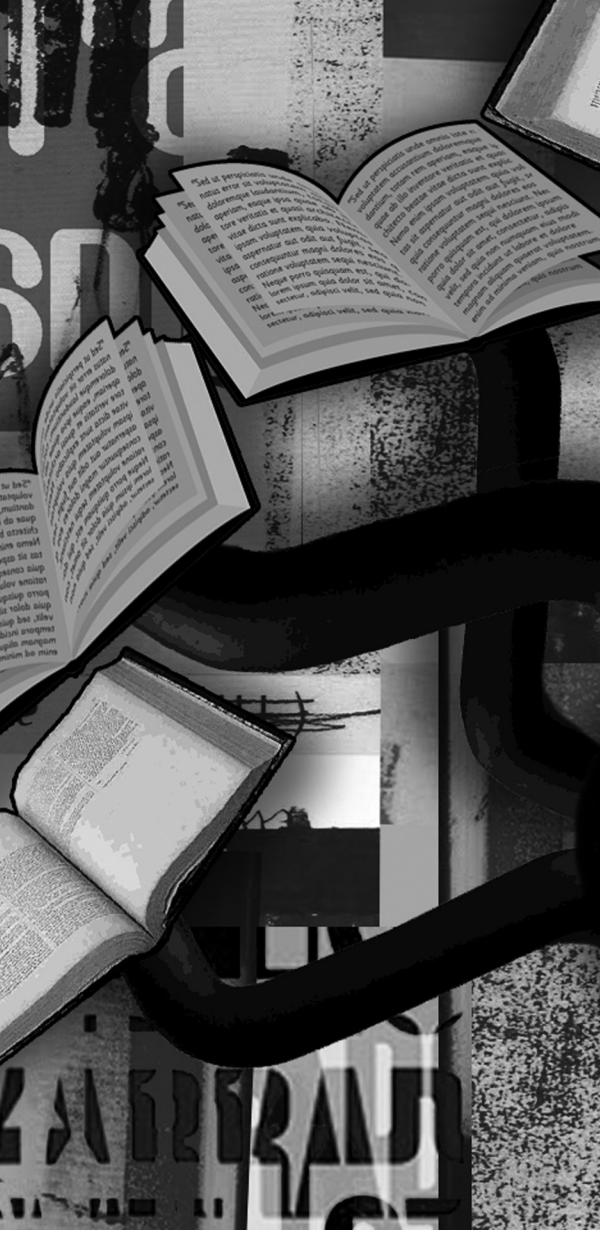

Desde un punto de vista interno, la escritura implica una lógica con reglas, operaciones y procedimientos comunes y necesarios para ser utilizada por distintos usuarios. Esta lógica debe ser interiorizada mentalmente en un proceso de enseñanza-aprendizaje pues la escritura no se aprende de manera "natural" (como se aprende a hablar o a caminar, aunque estos también son resultados de interacciones sociales), sino mediante una pedagogía mucho más compleja y prolongada.

Además de ser una tecnología, la escritura es también una institución social que se relaciona con otras instituciones sociales como la escuela, la religión, el ordenamiento jurídico-político, los medios masivos de comunicación ${ }^{5}$.

Desde nuestra perspectiva, ese carácter institucional se manifiesta mediante la existencia de los cánones de escritura, adscritos a las otras instituciones mencionadas, de las que se derivan formas de escritura canónica legitimadas socialmente. Por su carácter institucional, tales escrituras están investidas de un poder que se ejerce en las prácticas discursivas y comunicativas.

\subsection{El canon de escritura}

En un sentido general, el canon hegemónico de la escritura alfabética occidental es la forma como se reglamentan los modos de producir textos escritos. Está regulado por la norma lingüística y social, es decir, por una gramática y una pragmática dotada de sus respectivas instancias de control y fiscalización. Este canon de escritura está determinado por las instituciones que legislan y reglamentan los modos como los textos deben ser producidos lingüísticamente: las academias de la lengua, las gramáticas y los diccionarios que regulan la norma gramatical y la ortografía. Así mismo, está determinado por las directrices que representan los manuales de estilo, los editores y jefes de redacción, los comités editoriales y los correctores que vigilan y controlan la escritura para legitimar las formas como se debe escribir en una época, para un público, por un medio o en un soporte determinado, tal como sucede en los medios de comunicación (periódicos, revistas, noticieros) y en eventos de carácter académico (concursos, congresos, seminarios). El canon, como modelo hegemónico, es el que rige la producción textual en el campo de la educación, la ciencia, la cultura, el periodismo escrito en los distintos medios, el sistema jurídico y las leyes de un estado, cuyos textos están regidos tanto por normas gramaticales como por reglas de uso del lenguaje (reglas sociales), según el contexto que las origina, las exige y las legitima. Así por ejemplo, existen reglas para la escritura de textos periodísticos y guiones cinematográficos; para la redacción de códigos penales, leyes y decretos; o para la escritura de artículos científicos. 


\subsection{Canon y enunciación escrita}

Uno de los factores que han determinado la existencia del canon, es la naturaleza misma de la enunciación escrita, que se caracteriza por lo que llamamos la hipótesis de la doble ausencia: la del lector cuando el autor escribe y la del autor cuando el lector lee. En estas condiciones, es necesario que el autor realice una doble representación verbal en el texto: por una parte, el autor se representa a sí mismo mediante los pronombres personales u otros marcadores deícticos que constituyen la figura del enunciador responsable del enunciado. De igual manera, al escribir, el autor establece otras marcas a manera de pistas o indicios que orientan al lector sobre el modo como debe tomar los enunciados (si en sentido literal o metafórico, si como afirmación o como pregunta, si como copia literal o como paráfrasis de otro texto, si como verdad o como ironía, si como adhesión a un punto de vista referido o como confrontación del mismo). Por otra parte, el autor representa verbalmente al lector utilizando los pronombres de segunda persona y otros deícticos que constituyen la figura del enunciatario, es decir, de aquel a quien se dirige en su enunciado, en cuanto sujeto discursivo y no en cuanto sujeto físico.

El canon de escritura se ha consolidado en un largo proceso a lo largo de la historia hasta la actualidad. A partir del surgimiento y el auge de las tecnologías de información y comunicación, el canon -constituido fundamentalmente durante los cinco siglos de dominio del soporte impreso- se ha sido modificando, pues se han incorporado nuevas lógicas establecidas por la racionalidad del computador y de la internet. Un ejemplo de ello es la coexistencia en la red de textos escritos canónicamente, al lado de otros que no lo son, como puede suceder en los mensajes instantáneos o en los chats donde, además de los errores de redacción y de ortografía, es frecuente el uso de abreviaturas, grafismos y signos icónicos que hacen parte de un nuevo código de comunicación no verbal, en yuxtaposición con el lenguaje verbal.

Ahora bien, así como el canon es una instancia social en permanente transformación, no podemos hablar de la existencia de un único canon, sino de la coexistencia de distintos cánones, todos ellos hegemónicos en los diferentes contextos donde prevalecen. En ese sentido, desde nuestra perspectiva podemos hablar de la existencia de cinco cánones que responden a la misma norma gramatical y ortográfica, pero que se diferencian por sus reglas de uso y porque se inscriben en contextos sociales y culturales diferentes. Esos cánones son:

- El canon del discurso jurídico político que rige la escritura de las leyes, los decretos, los códigos y demás formas de reglamentación institucional.

El canon de los discursos mediáticos, que rige los procesos de producción textual y las estructuras discursivas de los medios de comunicación masiva. La radio, la prensa escrita, el cine, la televisión y la publicidad determinan diversas operaciones y procedimientos discursivos para la producción de sus mensajes verbales a través de los distintos géneros y formatos. Estos medios instauran incluso cánones particulares, dependiendo de la complejidad y la presencia en ellos de la imagen u otros sistemas no verbales de comunicación, como la música y el sonido. 
El canon literario, definido con relación a los textos que en una sociedad en un determinado momento de la historia se reconocen como literatura. En el caso particular del canon literario de occidente, éste se encuentra determinado por las instituciones que seleccionan los textos que deben ser leídos (y cómo deben leerse), respondiendo a unos criterios establecidos y a reconocimientos dados por la tradición cultural de un país, una época, un movimiento literario, o una concepción estética ${ }^{6}$.

- El canon del discurso científico en su acepción positivista, esto es empírica y demostrativa, propio de las ciencias "naturales y exactas".

- El canon del discurso filosófico y humanístico, que incluye a las ciencias sociales.

Tanto el canon del discurso científico como el del discurso filosófico y humanístico están relacionados con diferentes formas de exposición, argumentación y demostración. Ambos prevalecen en el mundo académico y en los procesos de enseñanza - aprendizaje en el sistema educativo. Otro tanto podemos decir del canon jurídico político. Ello explica la presencia de los textos expositivos, argumentativos y narrativos que contienen los conocimientos producidos y divulgados por diferentes medios, formatos, soportes y tecnologías. Es con base en estos dos cánones que se estructuran los currículos escolares, los manuales pedagógicos, los libros de texto y en general casi toda la bibliografía utilizada en el ámbito de la ciencia y la academia universitaria, que es el lugar objeto de nuestra investigación. Lo anterior no implica desconocer la presencia en el medio académico de los demás cánones, según la especificidad de los distintos campos del conocimiento.

El canon del discurso expositivo argumentativo se impone institucionalmente como la vía privilegiada de acceso al conocimiento por medio de la escritura y de un tipo de lectura que debe realizarse desde la perspectiva de la organización del texto. Aunque sabemos que un texto puede ser leído de muchas maneras, y en la práctica lo es, las estructuras textuales canónicas exigen una lectura acorde con su naturaleza lingüística y discursiva, como lo veremos más adelante. Por esta razón, es fundamental que los estudiantes conozcan el funcionamiento del canon, tanto para la producción como para la comprensión de los textos, puesto que es a través de los textos expositivos y argumentativos canónicamente escritos como se produce y se divulga el conocimiento científico y académico, aunque no están escritos para ellos. Pero antes que establecer o fijar el canon, el propósito de nuestro trabajo es indagar cómo funciona tanto en su lógica interna como en su eficacia pragmática, su carácter institucional, su valoración simbólica y su convivencia conflictiva con formas no canónicas en la sociedad. Dado que los cánones son un componente importante de la cultura escrita, nos interesa indagar también cuál es la relación de los estudiantes de la universidad con la cultura escrita y cuál es su grado de apropiación del canon correspondiente a los textos académicos científicos y humanísticos.

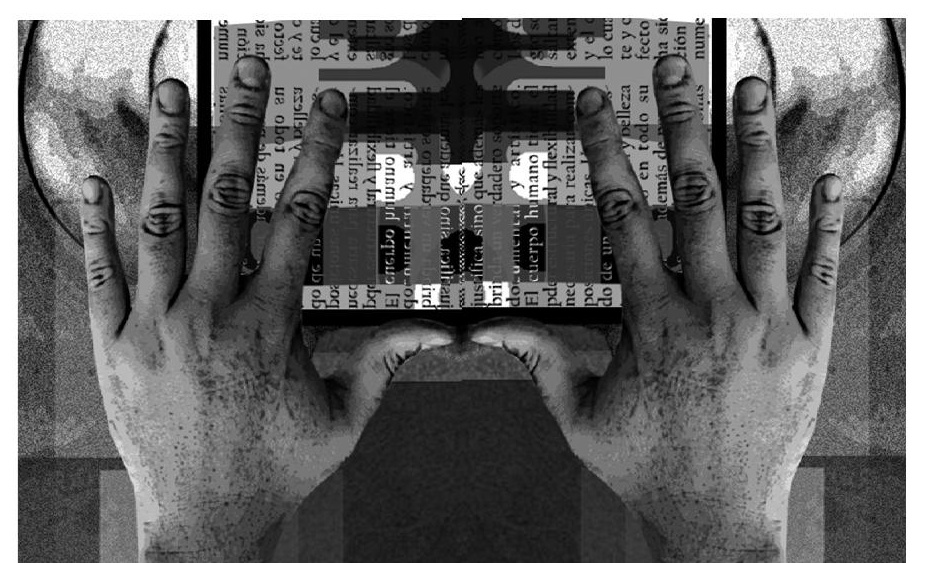


Los cinco cánones tienen en común el carácter histórico y cultural, es decir, cambiante, dinámico, siempre móvil entre la preservación de cierta normatividad y la emergencia de nuevas reglas; en una permanente tensión entre el canon estandarizado y las formas no canónicas que provienen de la diversidad sociodialectal del idioma, expresada sobre todo a través del habla y la oralidad ${ }^{7}$. La coexistencia conflictiva entre los diversos tipos de canon y los cánones particulares al interior de cada uno de ellos hacen parte de la comunicación social y académica, de las prácticas pedagógicas y los procesos de enseñanza aprendizaje.

El dominio del canon, en su acepción general, indica el grado de adscripción de las personas a la cultura escrita, y en ese sentido se encuentra en el centro de nuestro problema de investigación.

\subsection{La cultura escrita como mediación cognitiva}

La adscripción a la cultura escrita tiene al menos dos implicaciones interdependientes: por un lado, el dominio del canon a partir de una intensa relación con la escritura y la lectura; y por otro, la inserción en una tradición donde leer y escribir constituyen prácticas fundamentales en la vida cotidiana de sectores de la sociedad para los cuales la presencia del texto (manuscrito, impreso o electrónico) y sus usos intelectuales, tienen un alto valor práctico y simbólico. Caso contrario, al de aquellas personas que no han desarrollado las mismas competencias ni requieren de la lectura y la escritura para su desempeño social.

Desde un punto de vista sicolingüístico, leer y escribir, como prácticas de la cultura escrita, involucran complejos procesos mentales que implican el uso de distintos recursos -técnicos, informativos, lingüísticos, discursivos, cognitivos- y su aprovechamiento para analizar, interpretar, cuestionar o transformar los textos existentes y para crear nuevos textos. Por esta razón, no podemos reducir la cultura escrita alfabética a la idea tradicional de pensamiento ilustrado que supone la acumulación de contenidos informativos "universales" o "enciclopédicos" y que corresponderían a un saber declarativo (un saber qué). Además de este último, la cultura escrita alfabética comprende un sistema de conocimientos modales o procedimentales (un saber cómo, un saber hacer) relacionados con el leer y escribir, en tanto saberes específicos cuya práctica ejercida por grupos y comunidades, ha incidido significativamente en los cambios socioculturales del mundo occidental. La relación entre lectura, escritura y conocimiento se refiere tanto al conocimiento para poder leer y escribir desde la perspectiva de la organización del texto, como el conocimiento que se deriva de las prácticas de lectura y escritura.

La cultura escrita alfabética entraña una transformación cognitiva, no tanto por la suma de contenidos informativos que permite acumular, sino porque para poder leer y escribir canónicamente se requiere de un sistema de conocimientos prácticos (saberes procedimentales) que le permiten al lector: (a) entender la lógica desde la cual fue escrito el texto y sus relaciones intertextuales. (b) Leer desde la perspectiva de la organización del texto y no exclusivamente desde la cognición social del lector $\left.{ }^{8}\right)$; y (c) escribir según los parámetros establecidos en distintos contextos y por diferentes instituciones (escribir canónicamente).

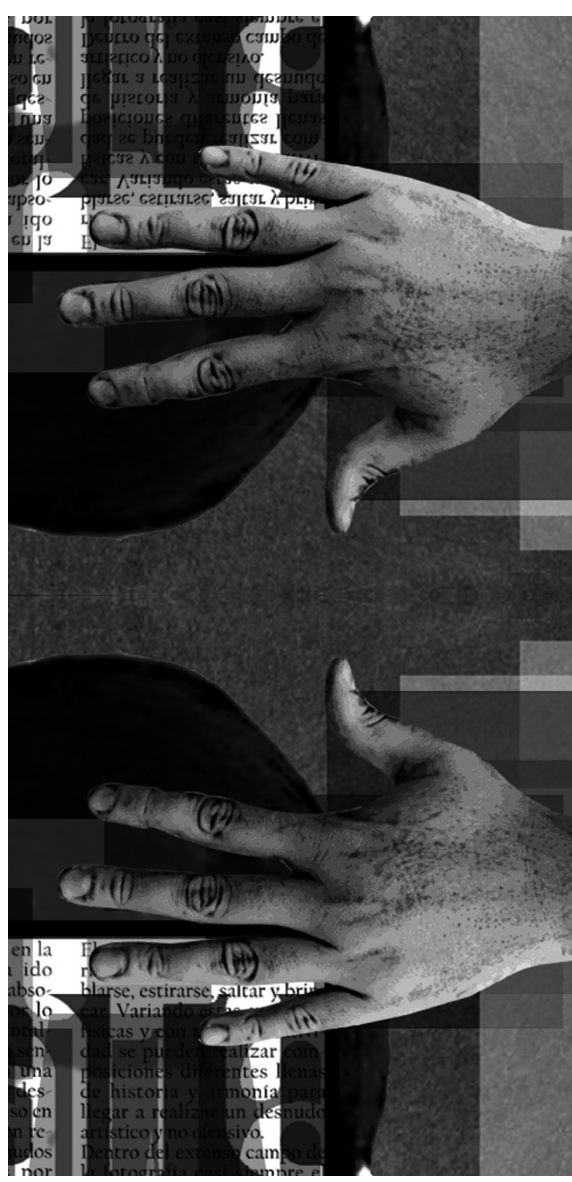


En otras palabras, la cultura escrita es una mediación cognitiva porque constituye un sistema de conocimientos procedimentales adquiridos, necesarios para el procesamiento, la apropiación y la producción de conocimientos semánticos especializados, como los que hacen parte del mundo académico universitario. La adquisición de esa mediación cognitiva supone una transformación de la conciencia, en el sentido de ser más consciente del lenguaje, del significado de las palabras, de los modos como están escritos los textos, de los modos como deben producirse y leerse, teniendo en cuenta su organización?.

\subsection{Tecnocultura y crisis de la cultura escrita}

La cultura escrita que hemos conocido se haya ahora sumida en un proceso de transformación cuyas fases de transición apenas podemos identificar. Tales transformaciones tienen directa relación con el surgimiento de lo que hemos denominado la tecnocultura contemporánea.

La tecnocultura, en un sentido amplio, se origina en el momento en que se inventa la escritura como una tecnología de comunicación e información. Más adelante, con el advenimiento de los medios de comunicación en el siglo XX y de las nuevas tecnologías de información y comunicación (Tics) al final del milenio, emerge una nueva fase de la tecnocultura, a la que denominamos "tecnocultura contemporánea".

Aunque la cultura escrita forma parte de la tecnocultura en un sentido amplio, la fase actual -ligada de manera directa a las Tics- constituye una nueva mediación cognitiva distinta a la mediación de la cultura escrita y hasta cierto punto independiente de ella. Es importante aclarar que no existe entre la cultura escrita (en adelante CE) y la tecnocultura contemporánea (en adelante TC) una relación evolutiva, en el sentido de que la nueva fase signifique la desaparición de la anterior. Por ello, pese al surgimiento de la TC, la CE sigue existiendo, incluso expresándose a través de los dispositivos electrónicos propios de la TC, como sucede con la escritura en el computador. Esta coexistencia en el tiempo y en el espacio tiene diferentes manifestaciones, como veremos más adelante cuando se presenten los resultados de la investigación.

\subsection{Jóvenes universitarios, cultura escrita y tecnocultura}

En el contexto de la modernidad, que da origen a la institución escolar, la cultura escrita alfabética constituye una mediación cognitiva indispensable en los procesos de apropiación, transformación y producción de los conocimientos escolarizados. Actualmente, bajo el predominio de los medios de comunicación y de las Tics, la CE está siendo "impactada" en sus distintas manifestaciones, aunque ello no signifique su desaparición.

Si bien, históricamente la educación se erigió bajo la égida de la CE, la gran mayoría de los estudiantes que hoy ingresan a la universidad colombiana han tenido un vínculo muy precario con aquella y con sus cánones; en contraste, están viviendo una intensa relación con las tecnologías audiovisuales y con las Tics. En otras palabras, percibimos un marcado desequilibrio en la relación de las nuevas generaciones con la $\mathrm{CE}$ y con la $\mathrm{TC}$, aunque

ambas coexistan dentro y fuera del mundo escolarizado y de ambas se deriven diversos tipos de conocimientos ${ }^{10}$. 
Asumimos, como parte del problema de investigación, que las dificultades de lectura y escritura de los estudiantes en la actualidad ${ }^{11}$-la distancia frente al canon de la cultura escrita alfabética y frente a los cánones existentes- no obedecen exclusivamente a las deficiencias del sistema educativo o de los métodos didácticos, a la mala "aplicación" de las teorías lingüísticas, ni a la indiferencia de los profesores que trabajan en áreas distintas a la enseñanza del lenguaje. Desde nuestra perspectiva, y sin ignorar estos factores asociados, las deficiencias al leer y escribir responden a múltiples y complejas determinaciones articuladas en el marco de la transformación cultural, bajo el predominio de los mass media y las nuevas tecnologías. Los cambios socioculturales en la historia reciente del mundo globalizado, afectan las relaciones de las nuevas generaciones con la $\mathrm{CE}$, lo cual se manifiesta en sus modos de leer y escribir, y en sus relaciones con el conocimiento académico especializado, en términos de su apropiación, usos y significaciones.

Entre las condiciones que propician tales cambios consideramos las siguientes:

La existencia de dispositivos tecnológicos distintos al libro u otros impresos, como espacios de circulación de información y de conocimientos, y como fuentes de acceso a los mismos.

- La preponderancia de la imagen en los discursos mediáticos y en los entornos virtuales.

- Las nuevas formas de relación entre lo oral y lo escrito propiciadas por los medios y las tecnologías (la mensajería instantánea, las redes sociales, el correo electrónico).

- La dedicación de un tiempo considerable al uso de dispositivos tecnológicos como los juegos electrónicos y el teléfono celular, a la recepción de los medios masivos -en particular la televisión-, al empleo del computador y de internet, estos últimos usados con diferentes fines, entre ellos la formación profesional universitaria.

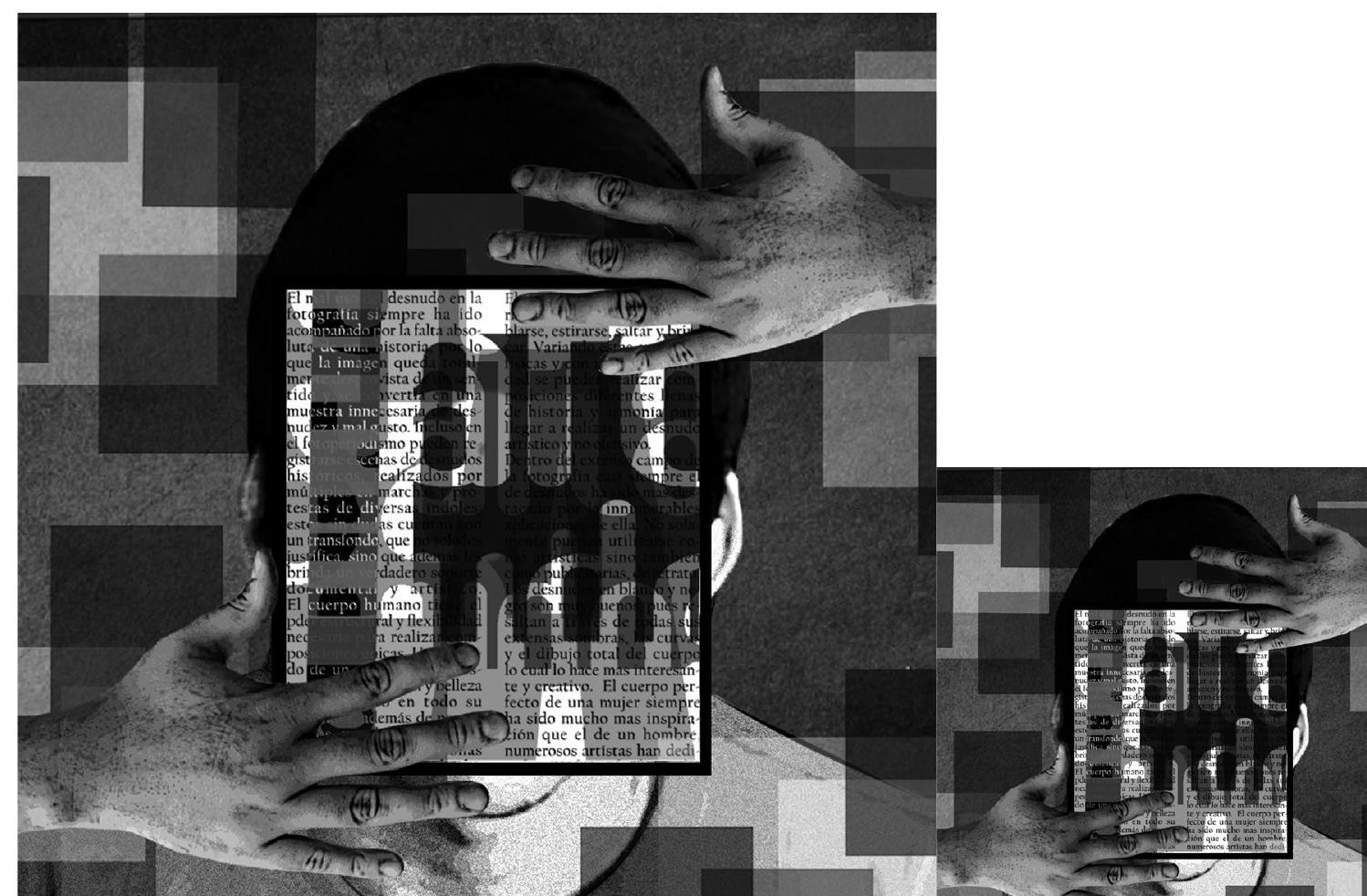




\section{Escritura, conocimiento y tecnocultura en la universidad (I Fase de la investigación)}

La primera fase de la investigación se propuso como un estudio exploratorio sobre las transformaciones en los modos de conocer de los jóvenes universitarios, representados en un conjunto de 259 estudiantes que cursaban su segundo semestre en las distintas carreras de la Universidad del Valle (jornadas diurna y nocturna). ${ }^{12}$ En términos generales, el objetivo fue realizar un diagnóstico sobre las condiciones en que se encontraban dichos estudiantes, en relación con la lectura, la escritura y el uso de dispositivos tecnológicos de comunicación e información, en tanto mediaciones de los conocimientos científicos, tecnológicos, artísticos y humanísticos, con los cuales se desarrolla la formación profesional universitaria. Para ello, se aplicaron los siguientes instrumentos:

A. Una encuesta, procesada estadísticamente, sobre sus prácticas de lectura y escritura -antes y después de su ingreso a la universidad-. En ella se indagaba también por el uso de tecnologías de comunicación e información, incluida la escritura.

в. Una prueba de lectura y escritura de textos expositivoargumentativos, como una forma de diagnosticar su relación con la cultura escrita, particularmente con los cánones del discurso científico, filosófico y humanístico. Se analizaron los resultados de manera independiente y se realizó un cruce de variables, de cuyas conclusiones surgieron nuevas hipótesis.

En los resultados de la investigación que se presentan a continuación, encontramos algunos indicios de la relación precaria de los jóvenes universitarios con la cultura escrita y algunas huellas de su adhesión a la tecnocultura contemporánea.

Algunos indicios sobre la relación de los jóvenes universitarios con la cultura escrita y la tecnocultura ${ }^{13}$.

A partir de la encuesta aplicada -en particular la sección que indagaba sobre las prácticas de lectura y escritura realizadas por los estudiantes durante sus estudios de secundaria- pudimos derivar las siguientes conclusiones:

A. En contraste con el desplazamiento de aquellas actividades que en los colegios promovían la relación con la lectura y la escritura (los centros literarios, los clubes de lectura, las tertulias, los grupos de estudio sobre temas políticos, artísticos, históricos u otros), asistimos al auge de otras formas de interacción auspiciadas por las Tics (las emisoras escolares, la comunicación a través de las redes sociales y el correo electrónico, el intercambio y la manipulación de imágenes y sonidos digitales). Aunque en las instituciones escolares persistan actividades ligadas al texto escrito, como el mural o la cartelera, la participación de los estudiantes en ellas es muy escasa, lo que evidencia, aún más, su desinterés por actividades que estén relacionadas con la cultura escrita. 
Sumado a lo anterior, la mayoría de los estudiantes que participaban en las publicaciones impresas y demás actividades extracurriculares vinculadas con la lectura y la escritura preferían desempeñarse en labores asociadas a formas de comunicación no verbal, y muy pocos optaban por la realización de actividades propias de la comunicación verbal escrita.

B. Con respecto a los modos de leer relacionados con la apropiación de conocimientos, encontramos que la actividad lectora de la mayoría de los estudiantes encuestados es bastante limitada. Poco están acostumbrados a actuar sobre el texto, a manipularlo, a usarlo, a dejar marcas sobre él (más allá de subrayar algunas partes). Incluso, la práctica del resumen (muy promovida por la institución escolar), en tanto forma de escritura que implica la producción de un texto a partir de otro, sólo es practicada por la mitad de los estudiantes encuestados. Para la mayoría, no parecen importantes actividades como relacionar diferentes partes del mismo texto de manera racional y atenta, establecer nexos con otros textos, e incluso escribir comentarios o interrogantes a partir de lo que leen. Estas actividades son propias de una minoría de alumnos universitarios.

c. Con relación a los conocimientos procedimentales vinculados a la tecnocultura contemporánea, el análisis de la encuesta permitió concluir que:

- La mayoría de los estudiantes (96\%) tiene un dominio básico del computador, expresado en el uso del procesador de textos, lo que nos habla de la relación que tienen con la escritura a través de un soporte distinto: la pantalla electrónica. Ello no significa, sin embargo, que tengan un dominio de los cánones de la escritura, pues éste último depende de factores como el capital cultural heredado y de la relación que en la escuela se haya logrado establecer con la cultura escrita ${ }^{14}$. Por otro lado, casi la mitad de los sujetos de la muestra manifestaron tener un dominio de programas para el procesamiento de la imagen, lo que resulta coherente con la importancia que los lenguajes no verbales tienen el ámbito de la tecnocultura contemporánea. Así, los saberes procedimentales derivados de las Tics estarían convirtiendo a estos jóvenes en creadores y manipuladores de imágenes, y no sólo en consumidores de las mismas, otro rasgo más de su adscripción a la tecnocultura contemporánea.

- La gran mayoría de los estudiantes que usan el computador acceden con regularidad a internet (97\%). El tiempo de conexión varía, dependiendo de factores como la disponibilidad del equipo (si se posee o no, si se utilizan los equipos dispuestos por la universidad o si se acude aun sitio público), el contar con el tiempo para esta actividad y el interés que despierte el recurso tecnológico en los estudiantes. 


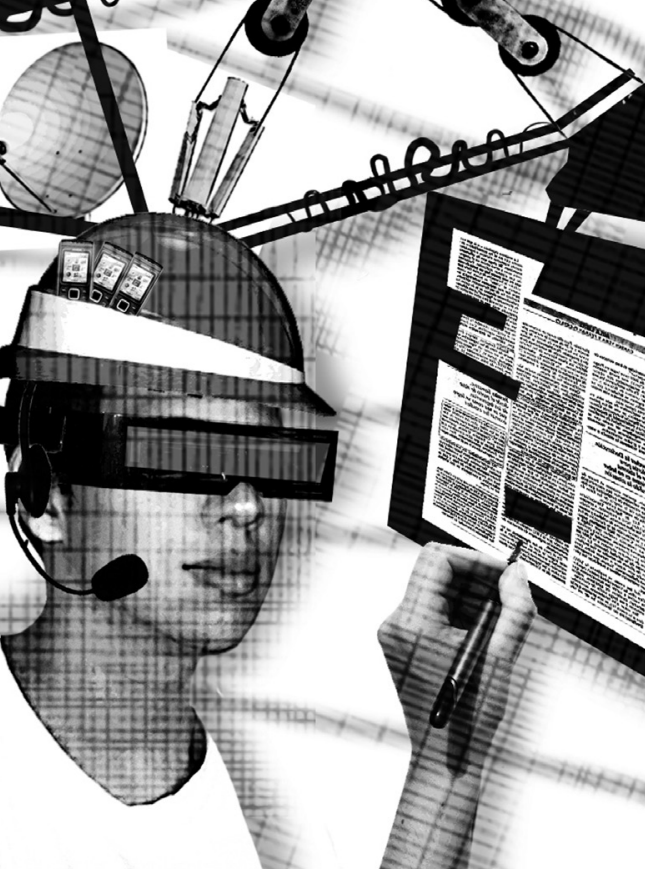

Según lo expresado por los estudiantes, la realización de tareas e investigaciones académicas es la principal motivación para acceder a internet. De ahí que la mayor parte de ellos decida archivar la información relacionada con su formación profesional.

Es muy probable que tal información sirva de base para la realización de trabajos universitarios, lo cual explica, a su vez, el que un número considerable de estudiantes manipulen de algún modo la información a la que acceden (cortan, ensamblan, quizás introducen pequeños pasajes elaborados por ellos mismos). Ese proceso podría concluir en la impresión de documentos que conformen el trabajo escrito o que sirvan de insumo para su elaboración. En cuanto al archivo de imágenes y de música, aunque es menos frecuente que el archivo de textos, constituye otro indicador de la importancia que el lenguaje audiovisual tiene para ellos. No obstante, es necesario tener en cuenta que este uso particular de internet (archivar imágenes y música) se concentra, según la investigación, en aquellos estudiantes que pertenecen a los estratos socioeconómicos más altos.

\subsection{Pruebas de lectura y escritura: comprensión y producción de un texto expositivo - argumentativo ${ }^{15}$}

La prueba diseñada consistió en leer un texto expositivo-argumentativo ${ }^{16}$ de una cuartilla, responder un cuestionario de 10 preguntas, expresar por escrito la tesis del autor y los argumentos con los que la sustenta, así como exponer su punto de vista personal sobre la tesis del autor y sobre el tema desarrollado en el texto ${ }^{17}$.

En lo que respecta a la lectura, la investigación puso en evidencia dificultades de los estudiantes en cuatro niveles:

- La identificación del punto de vista (o tesis) desarrollado por el autor en su texto.

El reconocimiento de los argumentos expuestos por él para sustentar su punto de vista.

- La identificación de los enunciadores ${ }^{18}$ y sus respectivos enunciados.

- La construcción de inferencias de cierto grado de complejidad, necesarias para la comprensión de los planteamientos del autor y del texto en general.

Con respecto a la prueba de escritura -que contemplaba una dimensión lingüística y una dimensión discursiva- ${ }^{19}$, los resultados fueron los siguientes:

La mitad de los textos producidos por los estudiantes presentaba problemas de coherencia local ${ }^{20}$, los cuales se producen, fundamentalmente por alguno de los siguientes errores: ruptura de la progresión temática, cambio abrupto de referente, abuso de implícitos, abuso de explícitos, mal uso de un conector, alteración fuerte del orden lógico de la oración o copresencia de algunas de los errores mencionados. La incoherencia local se produce cuando se presentan algunas de estas fallas, lo cual, a su vez, genera ambigüedad o indeterminación del sentido en el enunciado.

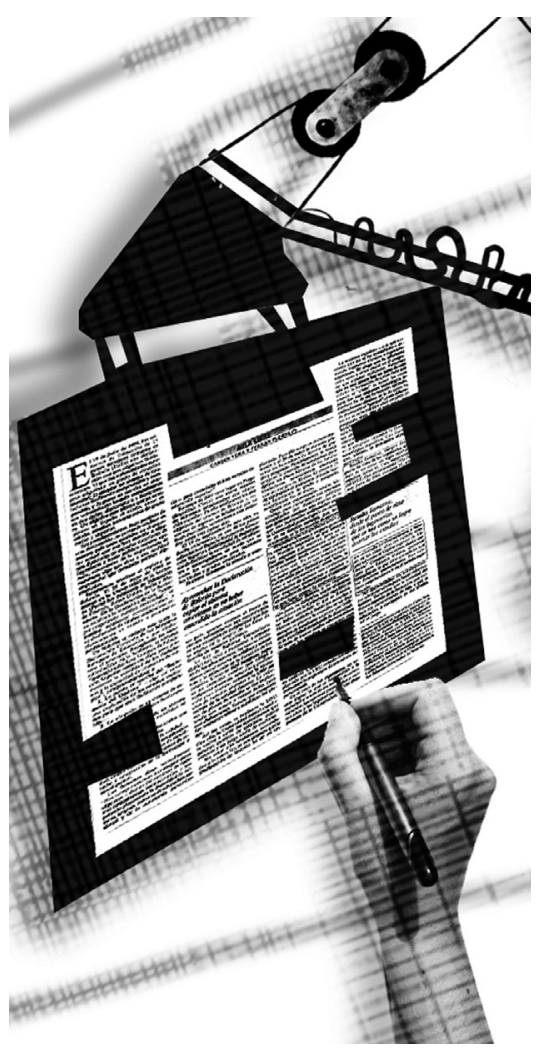


Aunque, en términos generales, el desempeño de los estudiantes en la dimensión lingüística fue adecuado, es preocupante que tantos estudiantes hayan presentado errores de coherencia local (53\%) pues esto tiene una incidencia directa en el otro componente de la prueba, es decir, la dimensión discursiva. En esta última se evaluó: la capacidad para identificar y formular en un resumen la tesis y los argumentos del autor del texto leído; el reconocimiento de los puntos de vista considerados por el autor del ensayo; la manera como los estudiantes representaban en su resumen los diferentes enunciadores reconocidos en la lectura; y la capacidad para presentar de manera clara, coherente y sustentada su punto de vista personal sobre el texto objeto de la prueba o sobre el tema desarrollado en el mismo. En todos estos niveles los estudiantes presentaron serias dificultades.

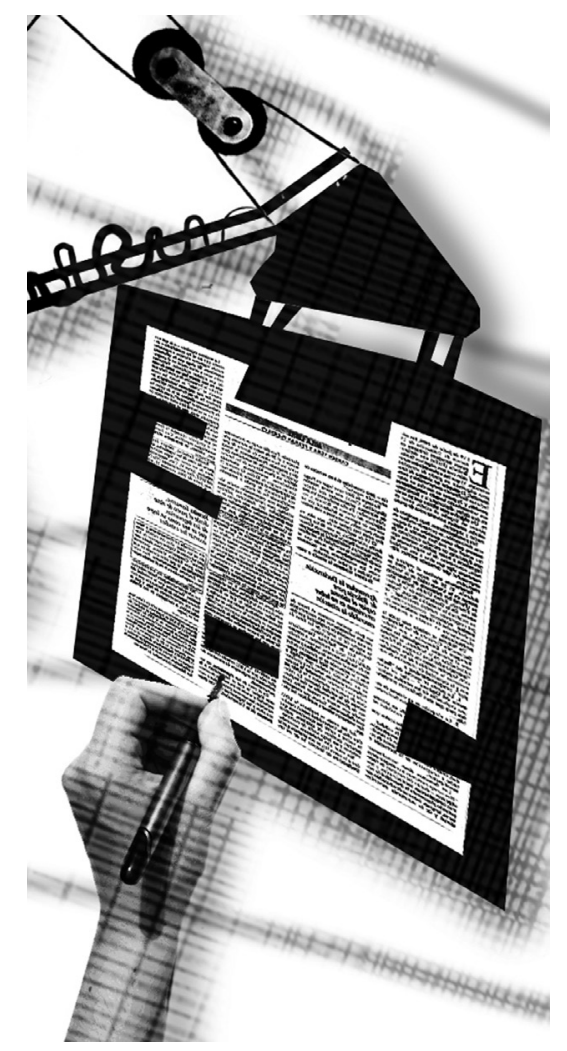

En numerosos casos, tuvieron problemas para reconocer y expresar por escrito el punto de vista o la tesis de un autor en su texto, dentro una estructura jerarquizada, en la que se diferencie de los argumentos y se identifiquen las relaciones entre ellos $^{21}$. Ello refleja, por una parte, el desconocimiento de las estructuras discursivas propias de los textos expositivo-argumentativos (es decir, el desconocimiento del canon que rige la escritura de este tipo de textos) y por otra, la escasa familiaridad de los jóvenes con el tema abordado en el texto leído.

En otras palabras, encontramos aquí una doble carencia: por un lado, falta de conocimientos previos sobre el tema, (por ejemplo, las diferencias entre la Constitución Colombiana de 1986 y la de 1991) y por otro lado, la falta de conocimientos procedimentales para diferenciar el enunciador dominante de los enunciadores referidos, reconocer los enunciados que se atribuyen a cada uno en el texto, identificar las oposiciones entre ellos, no sólo las oposiciones evidentes, sino las que se expresan de manera sutil, indirecta, o encubierta, bajo la metáfora, la ironía u otros recursos.

Con respecto a la representación de los distintos enunciadores incluidos por los estudiantes en sus resúmenes, encontramos errores de distinto tipo: (a) atribuir a un enunciador un enunciado expresado por otro; (b) atribuirse a sí mismos los enunciados de otros enunciadores; (c) no representar los enunciadores cuyos enunciados son retomados; (d) mezclar indiscriminadamente opiniones propias con los planteamientos del autor (el enunciador dominante) o de otros enunciadores; (e) reconocer la existencia de los enunciadores pero no representar los enunciados correspondientes, o representarlos parcialmente.

En conclusión, encontramos un tipo de lectura y escritura en la que no se considera necesario marcar los actos de enunciación (reconocer o identificar los enunciadores y sus respectivos enunciados) ni las relaciones de intertextualidad; un tipo que ignora, en muchos casos, la autoría y la confrontación de distintos puntos de vista para la construcción de una argumentación. Este tipo de lectura y escritura constituye, desde nuestra concepción teórica, un indicio de la débil relación de los estudiantes con el canon de la escritura expositiva-argumentativa, y en un sentido más amplio, con la cultura escrita en su conjunto. 
Si cruzamos los resultados arrojados en las pruebas con los datos derivados de la encuesta aplicada, podemos plantear que la experiencia escolar, las relaciones familiares y en general las diversas formas de interacción social de los estudiantes sujetos de nuestra investigación no les han permitido, a la gran mayoría de ellos, consolidar esa relación deseable y necesaria con la cultura escrita.

También en la formulación argumentada de su punto de vista personal hubo serias limitaciones, pues sólo el 7\% de los estudiantes pudo hacerlo, utilizando para ello referencias de apoyo debidamente articuladas (alusión a otros textos, películas, programas de televisión, casos de la vida real); el 29\% de los estudiantes expresó y desarrolló su punto de vista, pero sin utilizar referencias de apoyo. Un porcentaje también significativo (27\%) presentó de manera sucinta su punto de vista, aunque sin desarrollarlo, lo cual resulta aún más problemático. El 13\% de los estudiantes repitió o parafraseó el punto de vista del autor sin desarrollar el suyo propio, y el $24 \%$ expresó ideas incoherentes, no pertinentes, se contradijeron en sus planteamientos o no expresaron ningún punto de vista. Es decir, el 37\% contestó en términos que no correspondían a lo que se les estaba solicitando ${ }^{22}$.

Según estos resultados, los textos de los estudiantes presentaron problemas en la organización superestructural, es decir, en la orientación semántica y pragmática de su escrito como un todo expositivo-argumentativo, de acuerdo con unos requerimientos y propósitos comunicativos. En otras palabras, este grupo no logró expresar, ni argumentar su opinión de manera coherente. Estas dificultades en la dimensión discursiva de la escritura manifiestan una falta de coherencia global.

Al tomar en consideración los resultados de ambas pruebas (la de lectura y la de escritura), se encontró que un poco más de la tercera parte de los estudiantes (el 36\%) obtuvo una calificación inferior a 3. Esto resulta preocupante, por las siguientes razones:

Si consideramos que la cultura escrita constituye una mediación cognitiva en la formación académica, podría presumirse que este grupo de estudiantes se encuentra en condiciones precarias para la adquisición y procesamiento de conocimientos especializados, cuando estos procesos dependan de la lectura y la escritura de textos expositivo-argumentativos. Esto es aún más grave si se tiene en cuenta que el escrito empleado para la prueba es mucho menos complejo y denso que la mayoría de textos con los que los estudiantes deben enfrentarse a lo largo de su formación universitaria.

En lo que respecta al grupo más grueso de estudiantes, el 57\% tuvo un desempeño aceptable (calificaciones entre 3 y 4 ), es decir, presenta algunas deficiencias de lectura y escritura, fundamentalmente en la dimensión discursiva. Teniendo en cuenta lo anterior, estarían limitados para el desempeño óptimo de aquellas actividades de formación relacionadas con el análisis y la producción de textos expositivoargumentativos presentes en el medio académico universitario. 
Por último, sólo un escaso porcentaje de estudiantes (el 8\%) obtuvo calificaciones superiores a 4. Este grupo -cuya composición minoritaria es motivo de gran preocupación- es el que tiene una relación más próxima con la cultura escrita y por ello, desde nuestro punto de vista, tiene mejores posibilidades para desarrollar de manera eficiente actividades donde la lectura y escritura de textos expositivosargumentativos, sea un requisito fundamental.

Para quienes hablan de la sociedad del conocimiento, los resultados poco alentadores de este diagnóstico deberían ser considerados como un problema crucial, dado el valor estratégico que tiene la cultura escrita como mediación cognitiva y la necesidad de que en la educación se fortalezca la relación de los estudiantes con ella.

\section{Los estudiantes de la Universidad del Valle: su relación con la cultura escrita y la tecnocultura contemporánea (II Fase de la investigación)}

Para esta segunda fase, se aplicó una prueba similar a la primera, esta vez a 20 de los 260 estudiantes que conformaron la muestra inicial; también se realizó una entrevista que ampliaba la información aportada por la encuesta aplicada en 2003.

A diferencia de la primera investigación, en esta oportunidad no se procesó información estadísticamente, sino que se seleccionó un conjunto de los estudiantes que participaron en el primer proyecto y que se encontraban finalizando sus estudios universitarios. Dichos estudiantes fueron escogidos teniendo en cuenta su grado de adscripción a la cultura escrita (con base en los resultados de las pruebas de lectura y escritura aplicadas) y su relación con la tecnocultura (según datos derivados de la encuesta).

\subsection{Pruebas de lectura y escritura}

La prueba de lectura diseñada para la segunda fase de la investigación se propuso indagar en qué medida los estudiantes sujetos de la investigación -finalizando su carreraposeen y aplican los conocimientos procedimentales propios de la cultura escrita ${ }^{23}$. Se prestó especial atención a la capacidad de los estudiantes para hacer diferentes tipos de inferencias, así como a los conocimientos procedimentales requeridos para realizar una lectura de doble vía, ascendente y descendente (desde la cognición social del lector hacia el texto y a la inversa), reconociendo las marcas del texto, sus relaciones intertextuales, la presencia de distintos enunciadores y la elaboración implícita de la macroestructura del texto leído, como parte del proceso de comprensión. En la prueba de escritura se les solicitó una reflexión personal con el fin de evaluar su capacidad para relacionar conocimientos previos con conocimientos nuevos, representar distintos enunciadores según las necesidades del texto escrito y presentar un punto de vista personal con los argumentos que lo sustentan.

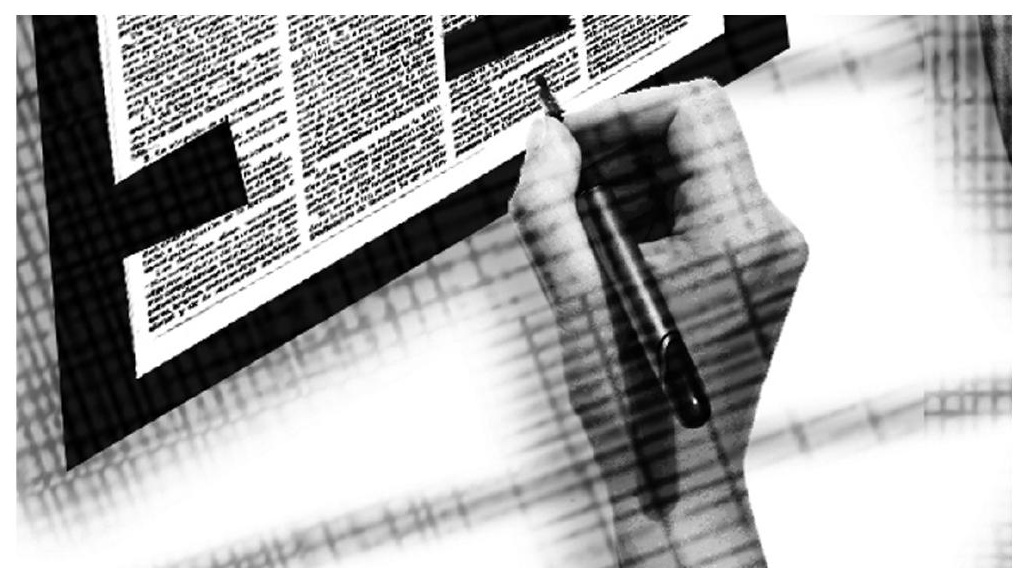


En ese sentido, la prueba se proponía diagnosticar la capacidad de los estudiantes para leer desde la perspectiva de la organización del texto y no sólo desde la perspectiva del lector y su cognición social; y relacionar sus conocimientos previos (semánticos y procedimentales) con los conocimientos nuevos aportados por el texto. ${ }^{24}$

Este modo de leer, requiere poner en acción (si se poseen) los siguientes conocimientos procedimentales en función de la prueba de lectura diseñada para esta investigación:

A. Realizar inferencias a partir de la relación entre conocimientos previos y conocimientos nuevos, tanto semánticos como procedimentales.

B. Identificar y reconocer:

- El enunciador dominante, con sus respectivos enunciados, diferenciándolo de los enunciadores referidos, no como un acto aislado sino en función de la significación global del texto y de sus significados particulares.

- Los enunciadores referidos con sus respectivos enunciados.

- Las paráfrasis, las ironías, los discursos directos e indirectos adscritos a sus respectivos enunciadores.

- Los puntos de vista, explícitos o no, de cada uno de los enunciadores presentes en el texto.

c. Reconocer la macroestructura del texto, como parte del mapa mental del significado, necesario para la comprensión por parte del lector.

D. Reconocer las superestructuras del texto expositivoargumentativo (problema- solución, paralelismo y contraste, tesis y argumentos, relaciones causa-efecto, definición y conceptualización...).

Insistimos en la necesidad de considerar los conocimientos previos de carácter procedimental, propios de la cultura escrita, que se requieren para leer desde la perspectiva de la organización del texto. Y es esto lo que evaluamos: si el estudiante posee o no tales conocimientos. En el diseño de la prueba asumimos que se trata de jóvenes colombianos, estudiantes universitarios que tienen información (conocimientos semánticos), sobre el tema tratado - el conflicto colombiano - así como sus propias opiniones al respecto. Sin embargo, aclaramos que el propósito de la prueba de lectura no era el análisis de sus opiniones, aspecto que sí fue considerado en la prueba de escritura, en la cual les solicitamos elaborar "una reflexión personal sobre la situación actual de la crisis colombiana teniendo en cuenta el texto leído”. 


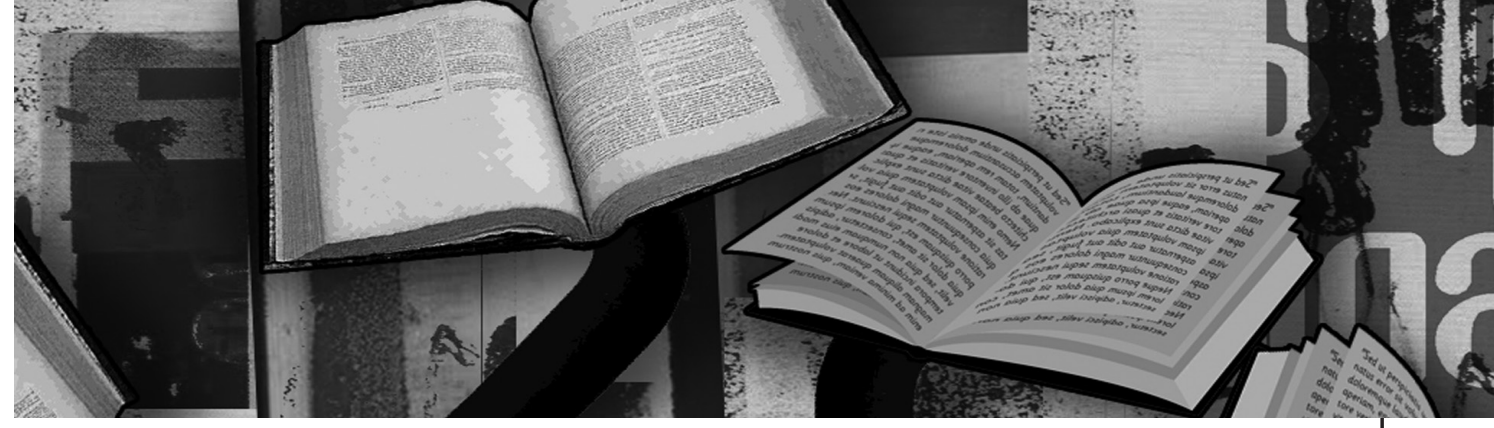

\subsection{Caracterización de la prueba}

El tex to empleado en esta segunda prueba de lectura fue creado por los investigadores, tratando de que fuera semejante al de la primera prueba, no tanto por su contenido sino por su estructura enunciativa y por su carácter expositivo-argumentativo. En este sentido, es un ensayo que presenta las siguientes superestructuras: (1) comparación y contraste, cuando describe las diferentes concepciones que tienen los actores mencionados frente al "conflicto colombiano"; (2) problema-solución, cuando identifica ese conflicto y explica las diversas "soluciones" propuestas por los actores involucrados; (3) tesis-argumentos, cuando fija una posición propia y se distancia de cada uno de ellos. Ahora bien, estas superestructuras están contenidas en una estructura enunciativa que las integra como elementos del texto expositivoargumentativo, objeto de análisis y evaluación en la segunda fase.

Con relación a la estructura enunciativa, el ensayo de la prueba presenta un enunciador dominante en forma impersonal que distribuye los turnos a diversos enunciadores referidos, cada uno de los cuales expresa sus puntos de vista frente al problema descrito. De esta manera, se presenta la intertextualidad y la confrontación de diversos puntos de vista con sus respectivos argumentos. La intertextualidad se manifiesta a través del discurso directo y mediante el discurso indirecto, la paráfrasis y la ironía, que deben ser inferidas por el lector. Esta exigencia -la de producir inferencias para comprender el texto y contestar acertadamente las preguntas del cuestionario- también estuvo presente en la prueba diseñada para la primera investigación. Para poder inferir, el lector debe identificar y diferenciar el enunciador dominante, los enunciadores referidos y sus respectivos enunciados y puntos de vista. En el cuestionario, las preguntas estaban dirigidas a indagar, indirectamente, por estos aspectos que hacen parte de los conocimientos procedimentales propios de la cultura escrita, teniendo en cuenta que éste es uno de los objetivos de la investigación.

\subsection{Resultados \\ Prueba de lectura}

Aunque en la segunda fase de la investigación no se implementaron herramientas estadísticas, presentamos los resultados tanto en cifras absolutas como en porcentajes, para destacar la proporción de estudiantes que tuvieron desempeños óptimos, regulares o deficientes.

En lo que respecta a la prueba de lectura, sólo tres de los veinte estudiantes evaluados (15\%) están en condiciones ideales pues respondieron acertadamente las cinco preguntas del cuestionario, lo cual indica su buen nivel de conocimientos procedimentales y su alto grado de adscripción a la cultura escrita, por lo menos en lo que concierne a la lectura de textos expositivo-argumentativos. 
Los doce estudiantes que acertaron en cuatro preguntas (60\%) aún carecen de ciertos conocimientos procedimentales, no leen plenamente desde la perspectiva de la organización del texto, no relacionan las partes que lo componen y les falta consolidar su capacidad para inferir. Como bien sabemos, estos aspectos son interdependientes para la comprensión.

Los cinco estudiantes que se equivocaron en dos o más preguntas (25\%) se encuentran distantes del modelo de lectura de los textos expositivos-argumentativos, requerido para la apropiación de ciertos conocimientos en el ámbito universitario.

\section{Prueba de escritura}

En esta prueba de escritura -en la que fueron evaluados 14 estudiantes $^{25}$ - seis (42.8\%) lograron una calificación superior a 4.0, pues sus textos evidencian un dominio básico de la dimensión lingüística y discursiva de la escritura de textos expositivoargumentativos, como el solicitado para la prueba. Cinco (35.7\%) obtuvieron calificaciones entre 3.0 y 3.9 pues presentan algunas dificultades tanto en el plano lingüístico como en el discursivo, de manera que están un poco más distanciados de la escritura canónica de textos expositivo-argumentativos. Finalmente, tres estudiantes $(21.4 \%)$ no tienen un dominio de los conocimientos procedimentales requeridos para escribir un texto expositivo-argumentativo a partir de la lectura del texto utilizado en esta fase de la investigación.

Las dos fases de la investigación han permitido ratificar la existencia de subgrupos de estudiantes con desempeños distintos en la lectura y la escritura de textos expositivo-argumentativos -como una expresión de su adscripción a la cultura escrita- y con distintas trayectorias en lo que respecta a su relación con la tecnocultura contemporánea. No obstante, todos ellos deben participar en procesos formativos homogéneos -que no reconocen los desniveles en sus capacidades- y deben someterse a mecanismos de evaluación que tampoco toman en cuenta sus carencias o potencialidades particulares, con las consecuencias negativas que este hecho trae consigo.

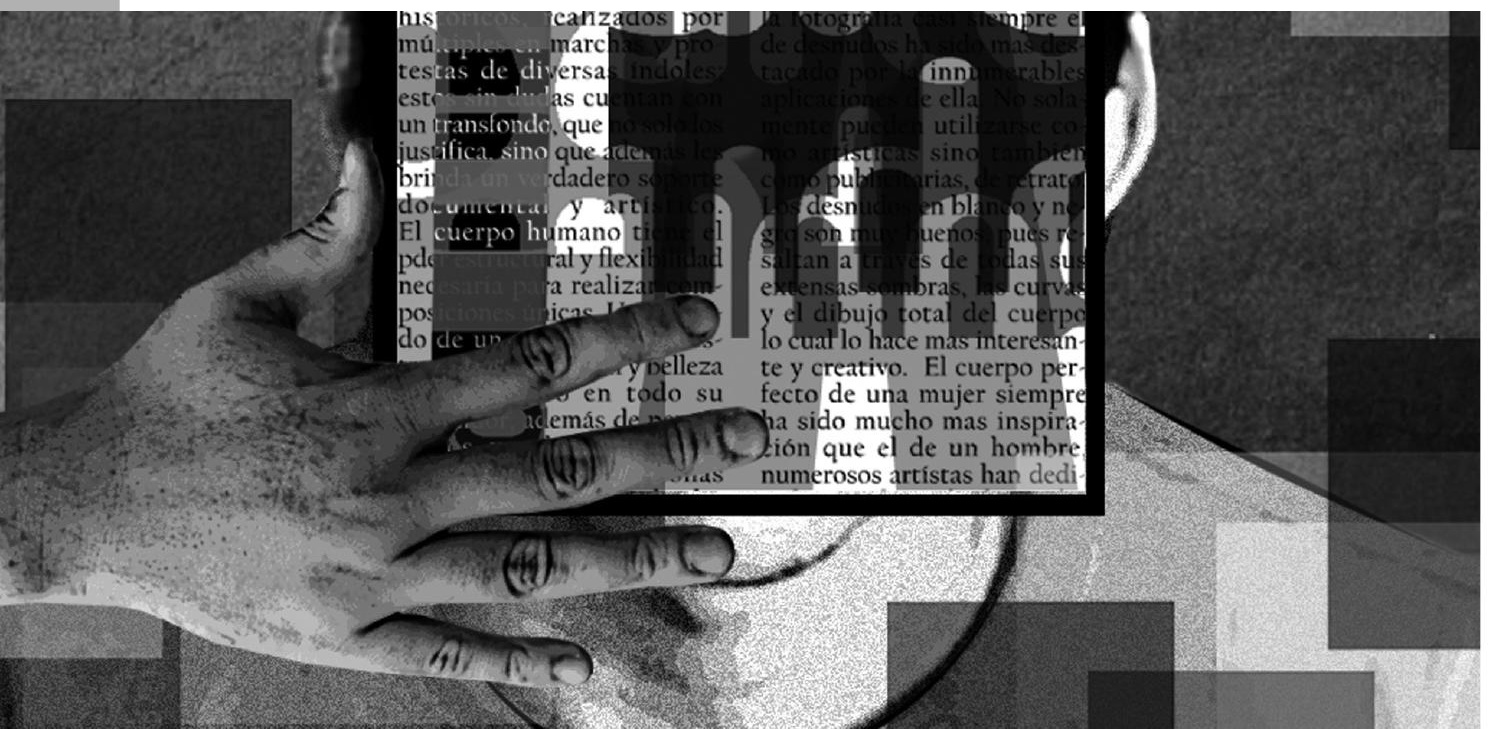


3. Persisten las problemas en la dimensión lingüística (puntuación, ortografía, sintaxis, coherencia local) y discursiva (reconocimiento y marcación de los enunciadores, identificación y representación de tesis y argumentos, desarrollo de puntos de vista personales argumentados), identificadas en la primera fase de la investigación.

4. No todos los estudiantes que obtuvieron un buen resultado en las pruebas iniciales de lectura y escritura se mantuvieron así en las finales.

5. No necesariamente un mal desempeño en la prueba de escritura inicial implicó un mal desempeño en la prueba de escritura final.

6. La investigación no ha permitido encontrar correlaciones constantes entre el desempeño en lectura y el desempeño en escritura. Tampoco entre los resultados de las pruebas y el promedio académico acumulado de los estudiantes en su carrera.

Con respecto a este último punto, tenemos la intuición de que para tener un buen promedio de calificaciones en la universidad - en tanto manifestación del desempeño académico de un estudiante ${ }^{26}$ - es suficiente con "hacerse entender" en los talleres, exámenes y trabajos escritos que los profesores asignan. Esto sin contar con que muchas veces los estudiantes son evaluados con pruebas de selección múltiple o "falso y verdadero" en las cuales no deben producir textos (además de que los profesores, con algunas excepciones, no se dedican a corregirles los textos). De hecho, en las pruebas de medición de desempeño académico implementadas por el Estado y por entidades particulares (Saber Pro, Pruebas Pizza, entre otros), se evalúa la lectura y no la escritura de los estudiantes. Es frecuente encontrar, en nuestras actividades pedagógicas, textos mal redactados por estudiantes que normalmente llegan a la universidad en condiciones precarias con respecto a la escritura, sin que la universidad haga mucho por mejorar su capacidad para escribir mejor. Muchos de sus textos son redactados de una forma no canónica, generalmente por desconocimiento de las operaciones y la normatividad que rige los discursos escritos en el ámbito académico universitario, que configura, en términos de Bourdieu, un mercado lingüístico específico.

Tales textos son presentados como trabajos para ser calificados, trátese de ensayos, informes, exámenes escritos, artículos, reseñas, o proyectos, de cuya evaluación se deriva la aprobación de una asignatura, la promoción para pasar de un semestre a otro, o incluso para graduarse con un título universitario. Ahora bien, ¿cómo asumen los docentes la relación con tales producciones verbales? ¿Con qué criterios se toman las decisiones para aprobarlo o no, ya sea una prueba parcial o un examen final? ¿Qué pasa cuando leemos textos con problemas de redacción, falta de coherencia, mala ortografía y puntuación inadecuada? Lo primero que sentimos, aparte de reconocer los problemas, es que el sentido del texto no es claro, es ambiguo o indeterminado. Esta es una queja cotidiana por parte de los profesores, (muchos de los cuales tampoco escriben muy bien) que parecen no ir más allá de la protesta espontánea y generalizada. Queremos llamar la atención sobre un procedimiento que posiblemente todos empleamos al leer dichos textos, como una forma de aprehenderlos mentalmente. 
Lo que hacemos espontáneamente es corregirlos en el instante, hacer los ajustes necesarios de sintaxis, puntuación y ortografía para tornarlos comprensibles. Disponemos de una especie de "mecanismo reparador" de la organización del sentido del texto que percibimos como algo mal construido en su nivel microestructural. (Algunas veces notamos también la falta de coherencia global). Este "mecanismo" se "dispara" automáticamente en nuestra conciencia para realizar una operación de ajuste, corrección y reparación del texto leído. De su acción instantánea dejamos algunas huellas visibles cuando escribimos preguntas o comentarios al margen, o cuando marcamos con algún signo alusivo a la falta de claridad, el léxico empleado y otros problemas que clasificamos genéricamente como problemas de redacción.

La acción del "mecanismo reparador" es rápida y relativamente exitosa, en tanto nos permite, una vez hecha la corrección, avanzar en la lectura para encontrarnos de nuevo en los próximos párrafos con casos semejantes, y ante la necesidad reiterada de volver a corregir. Este fenómeno, en sí mismo problemático, es de suma complejidad aunque nos parezca insignificante a la luz de nuestras rutinas como docentes y las formas de evaluación. Normalmente pasa desapercibido, entre otras cosas porque lo hemos convertido en una especie de acto reflejo que nos ayuda a "resolver" el problema de asignar una calificación, con toda la responsabilidad ética y académica que ello implica. Aquí queremos llamar la atención sobre el mecanismo descrito, preguntándonos inicialmente: ¿qué es lo que se repara en el texto? ¿Cómo es que ajustamos el sentido? ¿Desde dónde se activa el "mecanismo reparador"? ¿Qué consecuencias y qué implicaciones tiene esta acción en nuestras prácticas y particularmente en la evaluación? (si tenemos en cuenta que a partir de la reparación se toman decisiones cruciales como aprobar o no un curso, pasar un semestre, o aceptar una tesis de grado - mal escrita- conducente a un título profesional).

Lo que hacemos normalmente es corregir la ortografía, sobre todo aquella que afecta más directamente el significado, cuando genera ambigüedad o indeterminación semántica. Simultáneamente corregimos la sintaxis, reordenamos algunos fragmentos del texto, buscamos en el diccionario de nuestra memoria la palabra apropiada para remplazar la que nos parece inconveniente. En conjunto, establecemos los correspondientes significados, que suponemos, debe comunicar el texto. En un esfuerzo intuitivo y racional al mismo tiempo, y en un gesto de cierta complicidad con el estudiante - autor del texto evaluado - tornamos comprensible lo que en rigor no lo es.

La acción reparadora se convierte así en una estrategia de comprensión de lo leído, (en una instancia de control) como la única alternativa posible para poderlo asimilar. No siendo así, tendremos que desecharlo. De hecho, en los casos límite, el intento fallido de comprensión nos obliga a reprobar radicalmente el texto, o a exigirle a su autor una nueva elaboración, o la presentación de un trabajo distinto. Consideramos que el mecanismo de reparación funciona a partir del canon de escritura académica, canon desde el cual se corrige y se ajusta el texto, en sus niveles sintáctico-normativo y semántico-pragmático; tanto en las microestructuras como en las superestructuras que lo constituyen.

El canon, en tanto modelo, funciona como un programa en acción, es decir como un sistema en ejecución de sus reglas y operaciones fundamentales, con las cuales producimos los textos académicos (al menos los que se publican) y con las cuales se repara y se corrige, de manera "automática", lo que consideramos "mal escrito". 
Teniendo en cuenta lo anterior, podría plantearse que las deficiencias en la dimensión lingüística y discursiva de la escritura no afectan significativamente los logros académicos en términos de las calificaciones obtenidas. Sin embargo, las deficiencias identificadas sí podrían estar afectando su capacidad para derivar conocimiento de los textos que leen y para procesar en la escritura dicho conocimiento, como efectivamente lo indican los resultados de las pruebas aplicadas.

Según un estudio realizado en $2006^{27}$, la deserción en la Universidad del Valle es en promedio del 40\%. Las facultades con mayor deserción son Ciencias (54\%), Ingenierías (50\%) y Artes Integradas (44\%), y las de deserción más baja son Ciencias de la Administración (22\%) y Humanidades (29\%).

De igual manera, el estudio concluye que "no son, en estricto, las características personales de los estudiantes las que determinan la deserción de la Universidad sino que son aspectos de carácter académico las que lo determinan"28.

Nos preguntamos, entonces, si la relación precaria de los estudiantes con la cultura escrita no constituye una de las causas más importantes de la deserción en la Universidad del Valle. Si la deserción es superior al $40 \%$ en la mitad de las facultades y si algunos de los factores asociados a ella son de carácter académico, es factible suponer que la relación de los estudiantes con la cultura escrita incide de algún modo en su permanencia o no en la universidad. Muchos estudiantes que no han construido una significativa relación con la cultura escrita afrontan enormes dificultades cuando tienen que enfrentarse a textos expositivos-argumentativos densos, complejos y extensos que no han sido escritos para ellos pero que deben asumir plenamente sin estar preparados para hacerlo. Se trata de una dificultad real, frente a la cual la universidad debe plantearse soluciones concretas a la luz de futuras investigaciones que permitan profundizar en la comprensión del problema.
$\mathrm{Si}$ consideramos la relación entre los resultados obtenidos por los estudiantes en las pruebas aplicadas para esta investigación y el promedio de calificaciones de la carrera, encontramos los siguientes datos: De los diez estudiantes que obtuvieron 4.0 en la segunda prueba de lectura, siete tuvieron promedios académicos superiores a 4.0; y de los seis que sacaron más de 4.0 en la segunda prueba de escritura, sólo la mitad obtuvo promedios académicos superiores a 4.0. Esto indicaría que es más determinante el resultado de la prueba de lectura.

Finalmente, es importante tener en cuenta que el análisis comparativo de los resultados de las pruebas no puede presentarse de manera aislada. Dichos resultados, la información aportada por los estudiantes en la entrevista, la observación de textos académicos y no académicos proporcionados por ellos y el análisis de su trayectoria escolar, permitirán conocer en detalle el grado de adscripción de los sujetos de la investigación a la cultura escrita y su grado de pertenencia a la tecnocultura contemporánea, así como identificar posibles relaciones de tensión o de complementariedad entre ambas. La información obtenida nos permitirá profundizar sobre el papel de la universidad en la adscripción de los estudiantes a la cultura escrita y a la tecnocultura contemporánea, así como en las posibles correlaciones entre dicha adscripción y el rendimiento académico de los alumnos en la universidad, considerado este último como una de las manifestaciones de su nivel de apropiación de conocimientos especializados. 
La investigación realizada no se ha limitado a la cuantificación de los aciertos y los errores de los estudiantes examinados. Lo que también nos interesa indagar son las posibles explicaciones tanto de los errores como de los aciertos, con base en el modelo teórico que hemos propuesto desde la lingüística textual y la teoría de la enunciación como dos enfoques complementarios. Es desde ellos, mediante un proceso de argumentación lógica, que hemos podido vislumbrar las operaciones y los procedimientos implicados, las presuposiciones puestas en acción y las inferencias hechas o por hacer al momento de responder a las pruebas aplicadas.

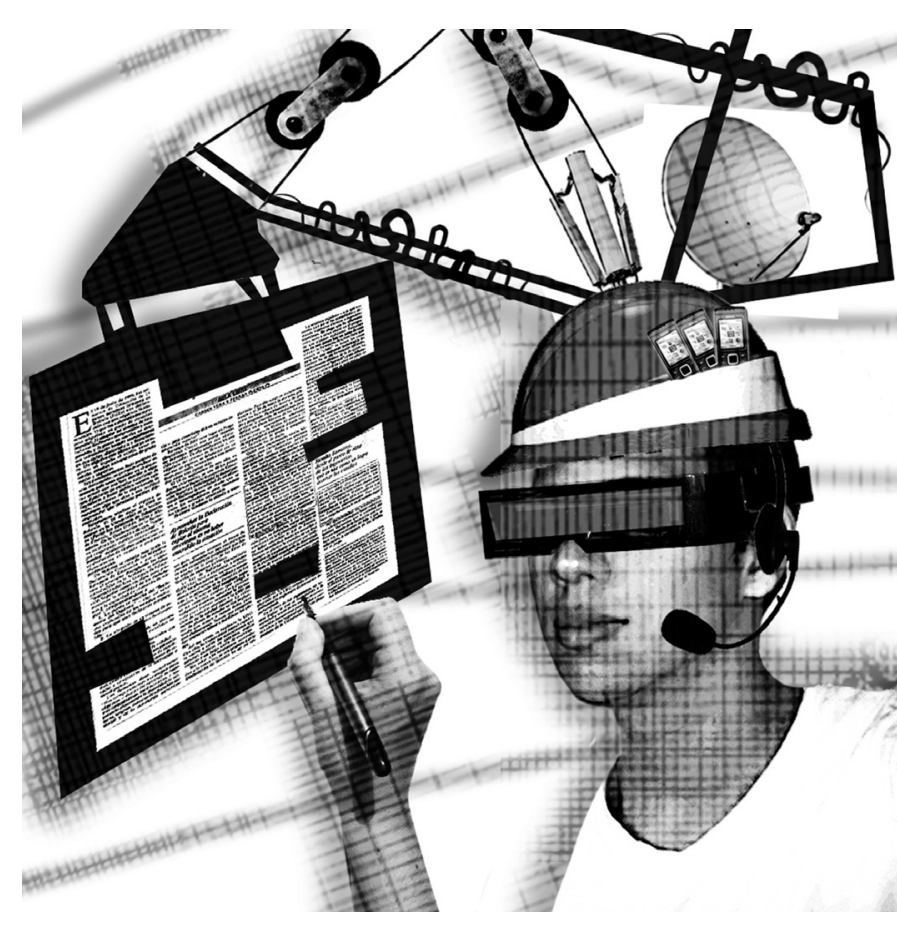

\section{Notas}

1 Integrante del grupo de investigación Escritura, Tecnología y Cultura. Comunicadora Social, Licenciada en Música y Magister en Comunicación y Diseño Cultural de la Universidad del Valle. Actualmente realiza el Doctorado en Ciencias de la Educación Rudecolombia, Universidad Tecnológica de Pereira.

2 La primera fase de la investigación fue realizada con el auspicio de Colciencias y de la Universidad del Valle, por los profesores Giovanna Carvajal, Griselda Gómez, Carlos Patiño y Alejandro Ulloa, de la Escuela de Comunicación Social de la Universidad del Valle.

3 La segunda fase de la investigación fue financiada por la Universidad del Valle, dentro de la convocatoria interna para proyectos de investigación, y fue desarrollada por los profesores Ulloa y Carvajal.

4 Marshal Mc Luhan en su libro La Comprensión de los Medios como Extensiones del Hombre (1969) y Walter Ong en Oralidad y Escritura, Tecnologías de la Palabra (1994), son los teóricos que han aportado de manera más significativa a la conceptualización de la escritura como tecnología, en sus dos dimensiones, externa e interna.

5 Para considerar la escritura como institución social nos basamos en Raymond Williams, en Historia de la Comunicación, Editorial Bosch, Barcelona, 1992.

6 Así por ejemplo, en nuestro contexto, el currículo escolar establece que se deben leer obras como Don Quijote, María, Cien años de Soledad, etc. En nuestra investigación, al indagar con los estudiantes por los textos leídos, aparece cada vez con más frecuencia, desde lo años 90, la literatura sobre "crecimiento y superación personal". Este "fenómeno" ha afectado el canon literario de nuestro sistema escolar, intervenido por el mercado editorial, principal promotor de dicha literatura. En conjunto, constituye una especie de canon comercial emergente, paralelo al canon literario escolarizado, al que parece haber erosionado en su hegemonía. El auge del "crecimiento personal" y la "superación individual”, es coherente con el auge de las ideologías neoliberales, de las que hace parte y a las que contribuye a reproducir. Faltan estudios que profundicen en la relación complementaria o no, conflictiva o no, entre los dos cánones mencionados, teniendo en cuenta la legitimidad adquirida por la ideología del "crecimiento personal”, dentro y fuera del ámbito escolar.

7 Así por ejemplo, el dialecto social de los "parceros" es altamente prestigioso al interior del grupo de pares, es decir en la comunidad de parceros; es también una forma de identidad lingüística y social incluso necesaria para su desempeño funcional en las interacciones entre ellos. Podríamos hablar de un canon dialectal, prestigioso en esa comunidad, valorado positivamente en ese mercado, pero desprestigiado por fuera de él. La predominancia de los dialectos sociales y regionales en la oralidad de los estudiantes se manifiesta lexical y sintácticamente en la escritura de sus textos, como lo hemos identificado en nuestra práctica docente. Ello expresa el conflicto entre oralidad y escritura, no en abstracto, sino en las prácticas sociales donde el habla como principal forma de comunicación, riñe con las formas canónicas de la escritura allí donde estas son requeridas por la sociedad; es decir, en los espacios donde los cánones de escritura son indispensables.

8 La cognición social se define como "un sistema de memoria a largo y corto plazo que almacena y retiene la representación semántica, permitiendo una recuperación posterior de los contenidos del texto", la cual puede ser retomada en el proceso de comprensión. La cognición social abarca saberes, prejuicios, valores, actitudes, ideologías y representaciones, desde los cuales se leen e interpretan los textos. T, Van Dijk, Análisis Crítico del Discurso, Universidad del Valle, Cali 1994. 
9 Así por ejemplo, la conciencia de la diferencia entre lo oral y lo escrito y sus posibilidades de uso en contextos diferenciados, es un producto de la cultura escrita alfabética y no una aprehensión innata del sujeto. Lograr una conciencia de esa diferencia, no es suficiente para empezar a escribir bien, pero sí constituye un paso fundamental para generar hábitos nuevos de carácter metacognitivo como: tener un mayor control sobre el léxico, la sintaxis y la puntuación; neutralizar la ambigüedad del sentido, cuando sea necesario; evitar la indeterminación del significado que resulta de los problemas morfosintácticos y lexicales; neutralizar las repeticiones innecesarias; analizar la pertinencia contextual de modismos y expresiones orales; y utilizar otros procedimientos útiles a la hora de escribir. Cuando esa diferencia se trabaja funcionalmente en los procesos de producción textual, ella implica una transformación cognitiva, altamente favorable para la escritura de los estudiantes, como lo hemos podido verificar en nuestra experiencia pedagógica. Así mismo, como mediación cognitiva, la cultura escrita proporciona los recursos lingüísticos y discursivos necesarios para hacer las inferencias en el texto escrito durante el proceso de lectura y comprensión textual. Si bien en la vida cotidiana todo el tiempo estamos produciendo inferencias, las inferencias que debemos realizar para generar nuevos conocimientos a partir de los textos escritos (independientemente del soporte) son de naturaleza distinta.

10 Lo que pretendemos desde la línea de investigación propuesta no es caer en una falsa dicotomía (rechazar la tecnocultura para afianzar los vínculos con la cultura escrita, o viceversa). Se trata, más bien, de analizarlas en sus múltiples articulaciones (tensiones, complementariedades) con el fin de aproximamos a una comprensión de los desafíos que asechan a la educación en general y a la formación universitaria, en particular.

11 Diversos estudios en países de América Latina (Britto, 1983; Pécora, 1984; Parodi y Núñez, 2002, Silvestri 2001, Ramírez, 2002) han encontrado problemas semejantes a los identificados en nuestra investigación. Por ello, podemos afirmar que las dificultades que presentan los estudiantes de distintos niveles de secundaria y universidad para la producción y comprensión de textos, no constituye un fenómeno aislado ni exclusivo de nuestro país. Incluso, aquello que nosotros denominamos la crisis de la cultura escrita se relaciona de algún modo con lo que H. Bloom (2000) y A. Petrucci (2001), han llamado la crisis del canon de occidente, aludiendo a Norteamérica y Europa Occidental.

12 La selección de la muestra poblacional se hizo con base en los datos suministrados por la oficina de Registro Académico de la Universidad del Valle, para identificar a los estudiantes de segundo semestre, hombres y mujeres entre 16 y 20 años de edad, que ingresaron en el año 2002. Resultaron 1757 estudiantes de segundo semestre, de los cuales se seleccionó una muestra aleatoria, estadísticamente representativa de los 54 programas académicos de pregrado existentes en esta Universidad. Finalmente, se seleccionaron 292 alumnos, previendo un margen de error del 10\% por dificultades en la aplicación de la encuesta y las pruebas, inasistencia, deserción de los estudiantes o negativas a ser parte de la muestra. En definitiva, se aplicaron la encuesta y las pruebas, a un total de 259 estudiantes, con un nivel de confiabilidad asumido del 95\%.

13 Un análisis preliminar de los resultados de la encuesta se publicó en Ulloa, A., Carvajal, G., "Jóvenes, Cultura escrita y tecnocultura”, Revista Anagramas, Volumen 3, número 6, junio de 2005, Universidad de Medellín. La encuesta aplicada incluía los siguientes capítulos: datos sociodemográficos; prácticas escolares de lectura y escritura; lectura, escritura y formas de sociabilidad; lectura y escritura para la apropiación de conocimientos; tecnocultura y conocimientos -usos del computador y de la televisión-.

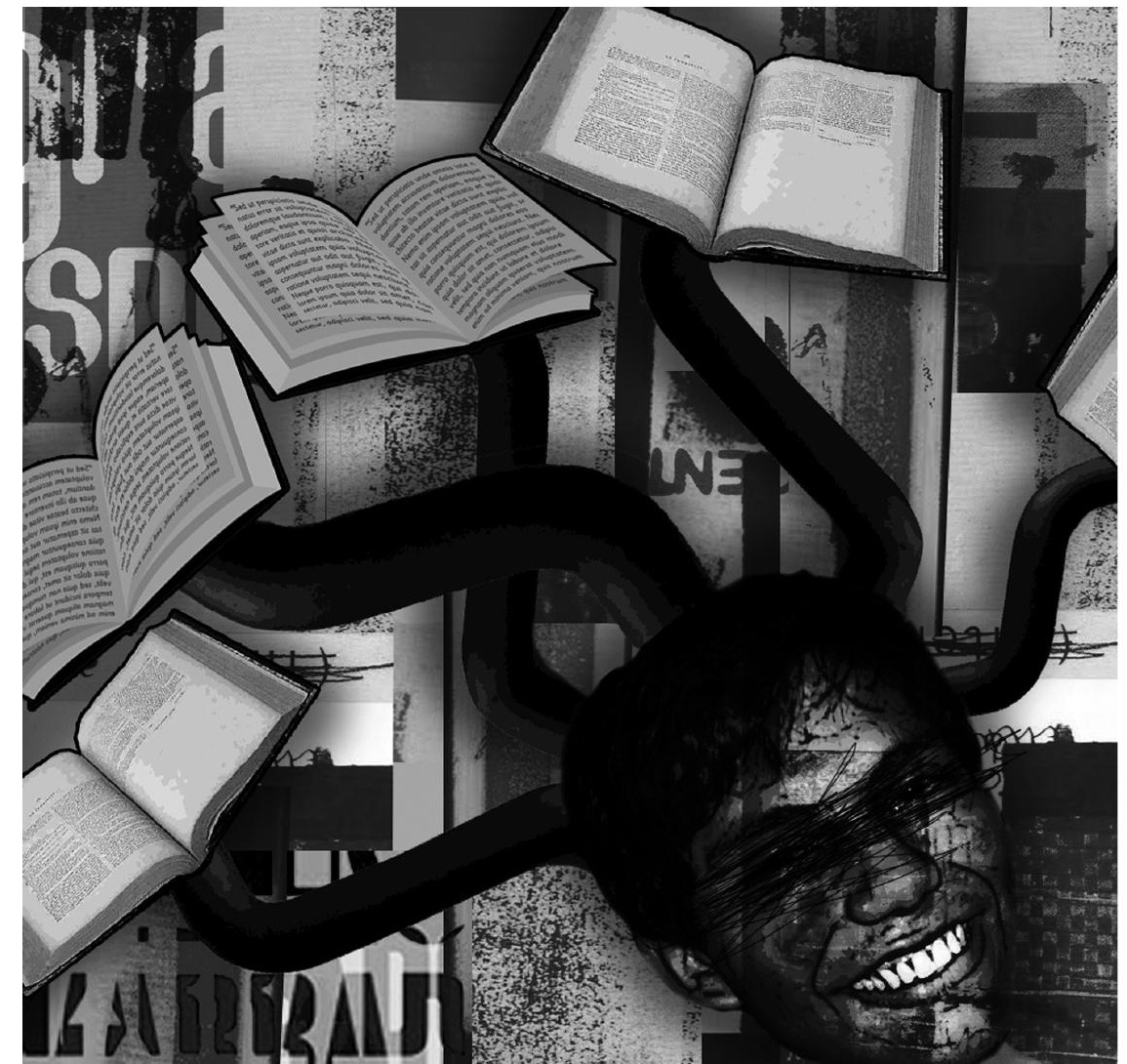


14 A partir de los resultados de las pruebas de lectura y escritura podemos afirmar que no se encontró una correlación directa entre el dominio de la tecnología y el dominio del canon de escritura.

15 El análisis de los resultados de las pruebas fue publicado en Ulloa, A., Carvajal, G., La lectura y la escritura de los estudiantes universitarios: una investigación exploratoria, Revista Lenguaje, $\mathrm{N}^{\circ} 32$, Escuela de Ciencias del Lenguaje, Universidad del Valle, noviembre de 2004, páginas 111 a 158. Las citas textuales corresponden a dicho artículo.

16 Como parte del marco teórico de la investigación, se propuso una tipología discursiva que reconoce cuatro tipos de discurso: narrativo, poético, expositivo y argumentativo. El tipo de texto empleado para las pruebas aplicadas en la investigación corresponde a lo que hemos denominado el híbrido expositivo-argumentativo. Ver Ulloa y Carvajal, Teoría del texto y tipología discursiva. En: Signo y Pensamiento, Editorial Pontificia Universidad Javeriana, Bogotá, No. 53, 2008, Págs. 295 - 313.

17 El texto seleccionado para las pruebas de lectura y escritura en la primera fase de la investigación es un ensayo titulado Eutanasia, del escritor Héctor Abad Faciolince (2002). En él se expone su punto de vista (tesis) frente a una decisión jurídica de la Corte Constitucional colombiana, con relación a la aplicación de la eutanasia en nuestro país. El fallo de la Corte determina que no se debe penalizar la eutanasia en Colombia, siempre y cuando el enfermo pida la muerte por piedad -como el autor prefiere llamarla-, y el médico que la practique esté de acuerdo. El fallo generó en su momento una intensa polémica en el país, dado que tanto la iglesia Católica como otros sectores de opinión se pronunciaron en su contra. El autor está a favor de la decisión de la corte y argumenta su tesis, confrontando otros puntos de vista que él analiza en el texto.

18 El enunciador se define como la figura verbal que en el texto "asume" (o sobre la cual recae) la responsabilidad de lo dicho en un enunciado. El enunciador, equivale a la figura que Ducrot (1988) llama "locutor" y se marca en el texto con un nombre propio, un pronombre personal o posesivo, y las desinencias verbales, con los cuales se puede reconocer e identificar con precisión. Diferenciamos al enunciador dominante (que representa verbalmente al autor en su ausencia) de otros enunciadores referidos con sus respectivos enunciados, bien sea a través del discurso indirecto o indirecto libre. Los contenidos del marco teórico correspondientes a la teoría de la enunciación se presentan en nuestro artículo "La enunciación en la construcción del texto escrito: formulación conceptual y pertinencia en una investigación sobre cultura escrita y conocimiento en la universidad”. Revista Nexus, No. 5 Universidad del Valle, Escuela de Comunicación Social, 2009

19 La dimensión lingüística comprende los aspectos sintácticos, semánticos y lexicales, fundamentales para una redacción apropiada de distintos tipos de textos. La dimensión discursiva se relaciona con los tipos de discursos y sus modalidades textuales, puestos en contextos socioculturales, en relación con las prácticas y los procesos de comunicación. Desde nuestra perspectiva, la dimensión lingüística y la dimensión discursiva son complementarias e interdependientes.

20 Según Van Dijk (1980), la coherencia local se produce en la microestructura de los enunciados (una frase, un párrafo) y es la que debe existir al interior de una oración o entre una secuencia de oraciones. Se diferencia de la coherencia global, pues esta última se refiere al significado general del texto a partir de las partes que lo componen (plano de la macroestructura). Los conceptos de micro y macroestructura, derivados de la lingüística textual de Van Dijk, se presentan en nuestro artículo "Lectura y Comprensión textual", publicado en la Revista Entreartes, No. 7, Universidad del Valle, 2008.

21 El 42\% de los estudiantes no pudo hacerlo y el 31\% expresó ideas incoherentes o no pertinentes. Sumando estos dos últimos porcentajes, encontramos que casi tres cuartas partes de los estudiantes, el 73\%, no expresaron la tesis del texto leído o la expresaron de manera incoherente.

22 Esto podría interpretarse como una forma de resistencia a la prueba; sin embargo, no se previeron mecanismos para verificarlo.

23 Como ya se dijo, la cultura escrita abarca conocimientos semánticos y conocimientos procedimentales específicos. Mientras los conocimientos semánticos aluden a un "saber qué", es decir, a saberes declarativos, los conocimientos procedimentales se refieren a un "saber cómo", un saber hacer. En el caso particular de la lectura y la escritura, los conocimientos procedimentales constituyen un "saber hacer" textos coherentes o un "saber hacer" para lograr la comprensión cuando se lee. Por ejemplo, no se trata sólo de saber qué son los marcadores deícticos (lo cual correspondería a un conocimiento semántico), sino de saber emplearlos adecuadamente en la construcción de un enunciado coherente o poder reconocer su significación en un determinado contexto cuando se trata de comprender un escrito. 
24 Como se ha expuesto en el marco teórico de esta investigación, diferenciamos los conocimientos previos de carácter procedimental, de los conocimientos previos de carácter semántico. En la mayoría de los estudios al respecto, no se hace esta distinción, pues cuando se habla de "conocimientos previos" se alude a conocimientos de carácter semántico y no a los procedimentales. Por ejemplo, identificar al enunciador dominante y reconocer los distintos enunciadores con sus respectivos enunciados y puntos de vista, presentes o implícitos, es un conocimiento procedimental, indispensable para la comprensión y por lo tanto para la apropiación de nuevos conocimientos semánticos.

25 Aunque las pruebas fueron aplicadas a los 20 estudiantes seleccionados para la segunda fase, sólo 14 de ellos pudieron ser entrevistados. El análisis de la prueba de escritura corresponde únicamente a los estudiantes que fueron entrevistados, a quienes además se les realizó un seguimiento de su trayectoria académica.

26 No pretendemos reducir el desempeño académico de los estudiantes al promedio de las calificaciones obtenidas, pues en una calificación numérica pueden incidir aspectos no relacionados con el grado de apropiación de los conocimientos en las distintas asignaturas. De todos modos, se trata de un referente numérico con el que operan todos los programas académicos de la universidad para medir el nivel de desempeño de los estudiantes.

27 Escobar, Jaime, Largo, Edwin, Factores asociados a la deserción y permanencia estudiantil en la Universidad delValle (1994-2006), Cidse, Facultad de Ciencias Sociales y Económicas, octubre de 2006, Cali.

28 Según el estudio citado, las variables académicas tienen que ver con el tipo de colegio del que proviene el estudiante, la jornada de estudios del programa académico, el rendimiento previo del estudiante (expresado en los resultados de las pruebas del ICFES), las pruebas específicas aplicadas por la universidad y el rendimiento obtenido en la universidad. Las demás variables consideradas fueron: individuales (edad de ingreso, género, estado civil, color de la piel); socioeconómicas (estrato y nivel de ingresos); hogar y procedencia de los estudiantes (convivencia con los padres, clima educativo del hogar, ciudad de origen); e institucionales (jornada, subsidio de bienestar universitario).

\section{Referencias}

Abad Faciolince, Héctor. (2002). Eutanasia, en: Palabras Sueltas, Editorial Planeta. Bogotá

Benveniste, Emile (1977) El Aparato Formal de la Enunciación, en Problemas de Lingüística General II, Siglo XXI Editores, México.

Bourdieu, Pierre, "El mercado lingüístico”, en Sociología y Cultura, Editorial Grijalbo, México, 1990.

Britto, Luiz P. (2003). La cultura Escrita y la formación del estudiante universitario, en Revista Lenguaje, número 31, Escuela de Ciencias del Lenguaje, Universidad del Valle, Cali, mayo.

De Torres. (1999). Julio Santiago, Procesos Psicológicos Básicos, editorial Mc Graw Hill, Madrid,

Ducrot, Oswald. (1988). Polifonía y Argumentación, Universidad del Valle, Cali.

Escobar, Jaime. (2003). “Caracterización socioeconómica de los estudiantes de la Universidad de Valle: progresividad y/ o regresividad en el cobro de matrículas”, en Universidad delValle: Reflexiones para un plan de desarrollo N. 1, serie Pensamiento Universitario, Cali.

Escobar, Jaime, Largo, Edwin. (2006).Factores asociados a la deserción y permanencia estudiantil en la Universidad del Valle (1994-2006). Cidse, Facultad de Ciencias Sociales y Económicas, Cali.

Fereiro, Emilia. (1999). Cultura escrita y educación. Conversaciones con Emilia Ferreiro, Fondo de Cultura Económica, México.

García Madruga, J., Elosúa, M. R., Gutiérrez, F., Luque, J. L., Gárate, M. (1999). Comprensión Lectora y Memoria Operativa, Ediciones Paidós Ibérica, Barcelona.

Greimas, A.J., Courtés, J. (1982). Semiótica. Diccionario razonado de la teoría del lenguaje, Editorial Gredos, Madrid

Jurado, Fabio V., Bustamante, Guillermo Z. (Compiladores.). (2001) Los Procesos de la Escritura, Editorial Magisterio, Bogotá.

López, Gladys Stella. (1996).Leer para Aprender, en Revista Lenguaje, Número 25, Universidad del Valle, Cali.

Mc Luhan, Marshal, "La palabra escrita: ojo por oído", en Comprender los medios de comunicación: las extensiones del ser humano, Paidos Comunicación, 1996.

Martínez, María Cristina. (2001). Análisis del Discurso y Práctica Pedagógica, Editorial Homo Sapiens, Buenos Aires. (2004). Estrategias de Lectura y Escritura de Textos. Perspectivas teóricas y talleres, Universidad del Valle, Cali.

Melo, Jorge Orlando. (2002). "Más libros y menos maestros”, en Revista El Malpensante \# 42, Bogotá, noviembre-diciembre.

Montenegro, Liliana, De Arnoux, Elvira, Bolívar, Adriana, López Gladys Stella, et al., (1997). Los procesos de la Lectura y la Escritura, Editorial Universidad del Valle, Cali,

Olson, David, (1994). El Mundo Sobre el Papel, Editorial Gedisa, Madrid., (1995) Cultura Escrita y Objetividad, Editorial Gedisa, Barcelona.

Ong, Walter. (1994). Oralidad y Escritura. Tecnologías de la Palabra, Fondo de Cultura Económica, Bogotá. 
